\title{
Karyotypic and molecular cytogenetic characterization of diploid and polyploid accessions of medicinal herbs in the genus Paris from northern Thailand
}

\author{
Janene Chow ${ }^{\mathrm{a}}$, Tidarat Puangpairote ${ }^{\mathrm{b}}$, Kesara Anamthawat-Jónsson ${ }^{\mathrm{c}}$, Puangpaka Umpunjun ${ }^{\mathrm{a}, *}$ \\ a Department of Plant Science, Faculty of Science, Mahidol University, Bangkok 10400 Thailand \\ b Deparment of Biology, Faculty of Science, Prince of Songkla University, Songkla 90110 Thailand \\ c Institute of Life and Environmental Sciences, School of Engineering and Natural Sciences, \\ University of Iceland, Reykjavík 102 Iceland
}

*Corresponding author, e-mail: puangpaka.ump@mahidol.ac.th

Received 20 Jan 2020

Accepted 19 Apr 2020

\begin{abstract}
Paris is a genus of medicinal plants in the family Melanthiaceae. For the use in traditional medicine and for trading in local markets, rhizomes of Paris plants are collected from their native habitats. Due to its slow growth and excessive harvesting, the species is currently facing the risk of extinction. The aim of the present study was to cytogenetically characterize Paris plants from the mountainous regions of northern Thailand in order to obtain characteristics that may be species-specific for use in taxonomical and diversity studies. Chromosomes were isolated from rhizome-grown root tips from the total of 20 Paris accessions. Of these, 12 were diploid $(2 n=2 x=10)$, 2 were triploid $(2 n=3 x=15)$, one was tetraploid $(2 n=4 x=20)$ and 5 were mixoploid accessions. The diploid accessions from Chiang Rai and Nan provinces had the most common basic karyotype $6 m+4 t$ whereas those from Chiang Mai province showed $6 m+4 s t$ and $4 m+2 s m+4 s t$, indicating differentiation at the species level. The analysis of karyotypes and ribosomal gene mapping by FISH (fluorescence in situ hybridization) indicated autotriploidy arising spontaneously within a diploid population and autotetraploidy via endoreduplication in the mitotic cell division. The ribosomal FISH also revealed a novel map of $5 \mathrm{~S}$ and $45 \mathrm{~S}$ rDNA, including the ancestral 5S-45S linked sites. The findings of our research support the ongoing species diversification among Thai Paris taxa.
\end{abstract}

KEYWORDS: chromosome, fluorescent in situ hybridization, karyotype, molecular cytogenetics, polyploidy, ribosomal genes

\section{INTRODUCTION}

Paris L. is a monocot genus in the tribe Parideae, family Melanthiaceae. The genus is mainly distributed in the temperate and subtropical zones of Europe and Asia [1]. According to Flora of China, there are 24 Paris species worldwide and in China 12 out of 22 Asiatic species are endemic [2].

The rhizome of Paris (called "Chonglou" in Chinese, and "Teen Hung Doi" in Thai) has been used in traditional medicine [3] for treatment of several conditions such as inflammations, injuries, fevers and wounds. Recent studies have shown that compounds extracted from Paris rhizomes also have anti-cancer properties. As many as 16 different compounds with anti-cancer properties have been identified in rhizomes of the Asiatic species P. polyphylla $\mathrm{Sm}$. [4]. Secondary metabolites from rhizome extracts such as saponins, dioscin, polyphyllin D and balanitin 7 have been shown to have anti-cancer properties in experiments using various cancer cell lines $[5,6]$. In the cytotoxic screening and apoptosis assays of the potential anti-cancer activity of some plants used in Thai traditional medicine [7], 2 out of 31 herbal extracts, i.e. methanol extracts of P. polyphylla var. chinensis (Franch.) $\mathrm{H}$. hara and Ficus thailandica C.C. Berg \& S. Gardner, showed potent anti-cancer (high apoptosis induction) activity, but had less effect on normal cells. Stemming from this, several studies have been initiated in order to identify species diversity of Paris in the mountainous regions of northern Thailand, aiming to provide knowledge for the species conservation and sustainable utilization. The present study is one of these projects.

Cytogenetic characteristics have often been used to help with the taxonomic classification of plants in the field of cytotaxonomy. For the genus 
Paris, all species recognized so far share the same base chromosome number $x=5$ [8-10], indicating noncomplex chromosome evolution with a single polyploid series. According to the Chromosome Counts Database (CCDB) [11], most of Paris species are diploid having 10 chromosomes in their vegetative cells $(2 n=2 x=10)$. Only a very few Paris species are polyploid. For example, the temperate Eurasian $P$. quadrifolia L. is essentially a tetraploid species with $2 n=4 x=20[12,13]$; the northern Asian and Siberian species $P$. verticillata M. Bieb. has tetraploid accessions [8] whereas the Japanese species $P$. japonica Franch is octoploid with $2 n=$ $8 x=40[12,14]$.

Karyotypic analysis is a cytogenetic means to provide a better insight into the phylogenetic relationship among closely related species. The karyotype is the morphological aspect of chromosome complement as seen at mitotic metaphase [15]. In the case of Paris, high-resolution karyotypes have been constructed using the heterochromatin staining methods of $\mathrm{C}$ - and Q-banding. The banding results from numerous Chinese and Japanese species have revealed the diploid basic karyotype formula to be $6 \mathrm{~m}+4 \mathrm{t}$, consisting of 6 metacentric chromosomes and 4 telocentric chromosomes, plus B chromosomes $[9,14,16]$.

The nucleolar organizer regions (NORs) have become part of the karyotype as their position on chromosomes is conserved to the point that it can reflect phylogenetic relationship among closely related species. The most common method for studying cyto- and phylogenetic relationship among closely related plant species is the method of fluorescence in situ hybridization (FISH) using ribosomal genes (rDNA) as probes [17-19]. In the case of Paris, the first report of rDNA-FISH is about the mapping of $18 \mathrm{~S}$ (45S) ribosomal RNA gene (rDNA) on chromosomes of 3 Paris species, 1 species from China: P. polyphylla $\mathrm{Sm}$. and 2 species from Japan: P. tetraphylla A. Gray and P. verticillata M. Bieb [20]. In all these 3 species, the $45 \mathrm{~S}$ rDNA loci are localized on acro-/telocentric chromosomes. In contrast, a different map of the 18-26S (45S) rDNA has been reported for 3 Paris taxa from China, P. polyphylla var. yunnanensis (Franch.) Hand.-Mazz., $P$. forrestii (Takht.) H. Li and P. axialis $\mathrm{H}$. Li [21]. No report on 5S rDNA mapping on chromosomes of Paris species from China and Japan is available.

There is no report on karyotypes or molecular cytogenetics of Paris plants from Thailand prior to the present study. The objectives are therefore (1) to evaluate $2 n$ chromosome number diversity among the Paris accessions collected from natural habitats in 3 provinces of northern Thailand, (2) to obtain karyotypic data for cytotaxonomical purposes and (3) to gain a better insight into the phylogenetic relationship among these Paris accessions by FISH mapping of $5 \mathrm{~S}$ and $45 \mathrm{~S}$ ribosomal genes. The results can be used to support the taxonomic classification of the unidentified Paris accessions in the present study.

\section{MATERIALS AND METHODS}

\section{Plant materials}

Living plant specimens (20 accessions) were collected from 3 Northern provinces of Thailand: Chiang Rai, Chiang Mai and Nan. Samples for the cytogenetic study were taken from these specimens before they were planted in greenhouse. Voucher specimens were deposited at Suan Luang Rama IX Herbarium. Source locations and accession numbers of plant materials used in the present study are shown in Table 1. All plant samples were identified under the supervision of Assist. Prof. Thaya Jenjittikul, Mahidol University, and Dr. Piyakaset Suksathan, Queen Sirikit Botanical Garden (QSBG), based on Flora of China [2].

\section{Cytological study}

Chromosome preparations were made from root tips using the Feulgen hydrolysis squash method [22] and the enzymatic squash method [18]. The root tips were pre-treated in ice-water at $4^{\circ} \mathrm{C}$ for $35 \mathrm{~h}$, or with saturated para-dichlorobenzene solution for $35 \mathrm{~h}$. After pre-treatment, the root tip samples were fixed and stored at $4^{\circ} \mathrm{C}$ in a $3: 1 \mathrm{v} / \mathrm{v}$ solution of ethanol and glacial acetic acid until use. For the Feulgen squash method, the fixed samples were washed in distilled water, followed by hydrolysis in $1 \mathrm{M}$ hydrochloric acid $(\mathrm{HCl})$ at $60^{\circ} \mathrm{C}$ for $8-10 \mathrm{~min}$, depending on root tip size. Then, each hydrolyzed root tip was squashed in $2 \% \mathrm{w} / \mathrm{v}$ of aceto-orcein stain. For the enzymatic squash method, the fixed root tips were digested in an enzyme mixture containing pectinase (30 units/ml, Merck no. 1.06021, Germany) and cellulase (80 units/ml, Merck no. 1.0232 , Germany) at $37^{\circ} \mathrm{C}$ for $12-15 \mathrm{~min}$. The digested root tips were squashed in $45 \%$ acetic acid. The slides were stored at $4{ }^{\circ} \mathrm{C}$ in dark and cool place until use. Some of these slides were used for metaphase analysis right away and therefore they were stained for $1 \mathrm{~min}$ with a $1 \mu \mathrm{g} / \mathrm{ml}$ solution of blue-fluorescing DAPI (4, 6-diamidino-2phenylindole, Sigma-Aldrich, USA). 
Table 1 Paris accessions under study and cytogenetic results.

\begin{tabular}{|c|c|c|c|c|c|c|}
\hline Species & Province & District & Accession no. & $\begin{array}{l}\text { Chromosome } \\
\text { no. }(2 n)\end{array}$ & $\begin{array}{l}\text { Karyotype } \\
\text { formula }\end{array}$ & Ploidy \\
\hline $\begin{array}{l}\text { Paris polyphylla } \\
\text { var. chinensis }\end{array}$ & Chiang Rai & Mae Saruay & $\begin{array}{l}\text { PP } 035807 \\
\text { PP } 035810\end{array}$ & $\begin{array}{l}10 \\
10\end{array}$ & $\begin{array}{l}6 m+4 t \\
6 m+4 t\end{array}$ & $\begin{array}{l}\text { Diploid } \\
\text { Diploid (Fig. 2B, 3A-B) }\end{array}$ \\
\hline Paris sp. & Chiang Rai & Pang Khon & PJPK 621114-1 & 10 & - & Diploid (Fig. 2C) \\
\hline $\begin{array}{l}\text { Paris cf. cronquistii } \\
\text { var. cronquistii }\end{array}$ & Nan & Mae Jarim & $\begin{array}{l}\text { PPNN } 5926 \\
\text { PPNN } 5935 \\
\text { PPNN } 59059 \\
\text { PPNN } 59242\end{array}$ & $\begin{array}{l}- \\
10 \\
15 \\
10\end{array}$ & $\begin{array}{l}- \\
6 m+4 t \\
9 m+6 t \\
6 m+4 t\end{array}$ & $\begin{array}{l}\text { Diploid (Fig. 4A-B) } \\
\text { Diploid (Fig. 2A) } \\
\text { Triploid (Fig. 2H, 3G-H) } \\
\text { Diploid (Fig. 3C-D) }\end{array}$ \\
\hline Paris spp. & Chiang Mai & $\begin{array}{l}\text { Doi Pu Muen } \\
\text { Doi Saket } \\
\text { Mae Chon Luang } \\
\text { Mae Khi } \\
\text { Mae Rim } \\
\text { Mae Taeng } \\
\text { Phraphutthabat Si Roi }\end{array}$ & $\begin{array}{l}\text { PJPM 62004 } \\
\text { PJKL 006 } \\
\text { PJMJ2 008 } \\
\text { PJMK 62018 } \\
\text { PJHL 621112-7 } \\
\text { PJMT 521113-15 } \\
\text { PJMT 621113-3 } \\
\text { PJPPB 62004 } \\
\text { PJPPB 62017 } \\
\text { PJSM2 012 } \\
\text { PJSM2 013 } \\
\text { PJSM2 } 014 \\
\text { PJSM2 } 015\end{array}$ & $\begin{array}{l}10 \\
10 \\
15 \\
10 \\
15 \\
10 \\
10 \\
20 \\
10 \\
10 \\
20 \\
10 \\
15 \\
10 \\
10 \\
20 \\
10 \\
20\end{array}$ & $\begin{array}{c}6 \mathrm{~m}+4 \mathrm{st} \\
- \\
- \\
- \\
- \\
- \\
- \\
- \\
- \\
- \\
- \\
- \\
- \\
- \\
4 \mathrm{~m}+2 \mathrm{sm}+4 \mathrm{st} \\
8 \mathrm{~m}+4 \mathrm{sm}+8 \mathrm{st} \\
6 \mathrm{~m}+4 \mathrm{st} \\
-\end{array}$ & $\begin{array}{l}\text { Diploid (Fig. 4C-D) } \\
\text { Diploid } \\
\text { Triploid } \\
\text { Diploid } \\
\text { Triploid } \\
\text { Diploid } \\
\text { Diploid } \\
\text { Tetraploid (Fig. 2J) } \\
\text { Diploid (Fig. 4E-F) } \\
\text { Diploid } \\
\text { Tetraploid (Fig. 2K) } \\
\text { Diploid (Fig. 2E, 4G-H) } \\
\text { Triploid } \\
\text { Diploid (Fig. 2D) } \\
\text { Diploid (Fig. 2G, 3E-F) } \\
\text { Tetraploid (Fig. 2I, 3I-J) } \\
\text { Diploid (Fig. 2F) } \\
\text { Tetraploid }\end{array}$ \\
\hline
\end{tabular}

The chromosome number of each plant was determined from images of metaphase cells from either orcein- or DAPI-stained slides, taken at $1000 \times$ magnification using an Olympus DP50 ${ }^{\circledR}$ digital camera operated with Olympus BX50 fluorescence microscope. Karyotypes were constructed from the best images for each accession according to the standard method [23], based on arm ratio measurements.

\section{Fluorescence in situ hybridization (FISH)}

FISH experiments were conducted as previously reported [18], with only minor modifications. Chromosome preparations for FISH experiments were obtained using the enzymatic squash technique as described above. Two ribosomal probes were used in the present study: 5S rDNA probe from the plasmid clone pTa794 and the 45S rDNA probe from the plasmid clone pTa71. The rDNA probes were labelled separately with different fluorochromeconjugated nucleotides by standard nick translation: the $5 \mathrm{~S}$ rDNA probe with the green label Fluorescein12-dUTP (Roche Applied Science, Germany) and the $45 \mathrm{~S}$ probe with the red-fluorescing SpectrumReddUTP (Vysis, USA).

The chromosome preparations were first digested with RNase-A $(5 \mu \mathrm{g} / \mathrm{ml})$ for $1 \mathrm{~h}$ at $37^{\circ} \mathrm{C}$ and treated with paraformaldehyde $(4 \% \mathrm{w} / \mathrm{v})$. The probe mixture for each slide consisted of $50 \mathrm{ng}$ each of the red- and green-labelled rDNA probes,
$50 \%$ formamide, $20 \%$ dextran sulphate, $2 \times$ SSC and $0.5 \%$ SDS. The combined denaturation was carried out for $10 \mathrm{~min}$ at $89^{\circ} \mathrm{C}$ in a PTC-100 Programmable Thermocycler (MJ Research, USA), followed by an overnight hybridization at $37^{\circ} \mathrm{C}$. The post-hybridization washing steps included a stringent wash in $0.1 \times \mathrm{SSC}$ at $55^{\circ} \mathrm{C}$ for $15 \mathrm{~min}$.

The chromosomes were stained for 1 min with a $1 \mu \mathrm{g} / \mathrm{ml}$ solution of fluorochrome DAPI and mounted with the antifade Citifluor AF1 (Citifluor, UK). The FISH signal on chromosomes was examined under $1000 \times$ magnification in the Nikon Eclipse E800 epifluorescence microscope. The images were captured with Nikon Digital Camera DXM1200F. The FISH hybridization signals of 5S and $45 \mathrm{~S}$ rDNA repeats were mapped on metaphase chromosomes in the form of ideograms.

\section{RESULTS}

\section{Plant morphology}

Large morphological variation was found among Paris plants in this study, especially in number of ovules, type of placentation, number of stamen, shape of outer and inner tepals, number of leaves per node and additionally in some cases leaf morphology and rhizome shape and size (Chow et al, manuscript in preparation). The accessions from Chiang Rai province, i.e. from Mae Saruay district, belong to P. polyphylla var. chinensis (Fig. 1A) 

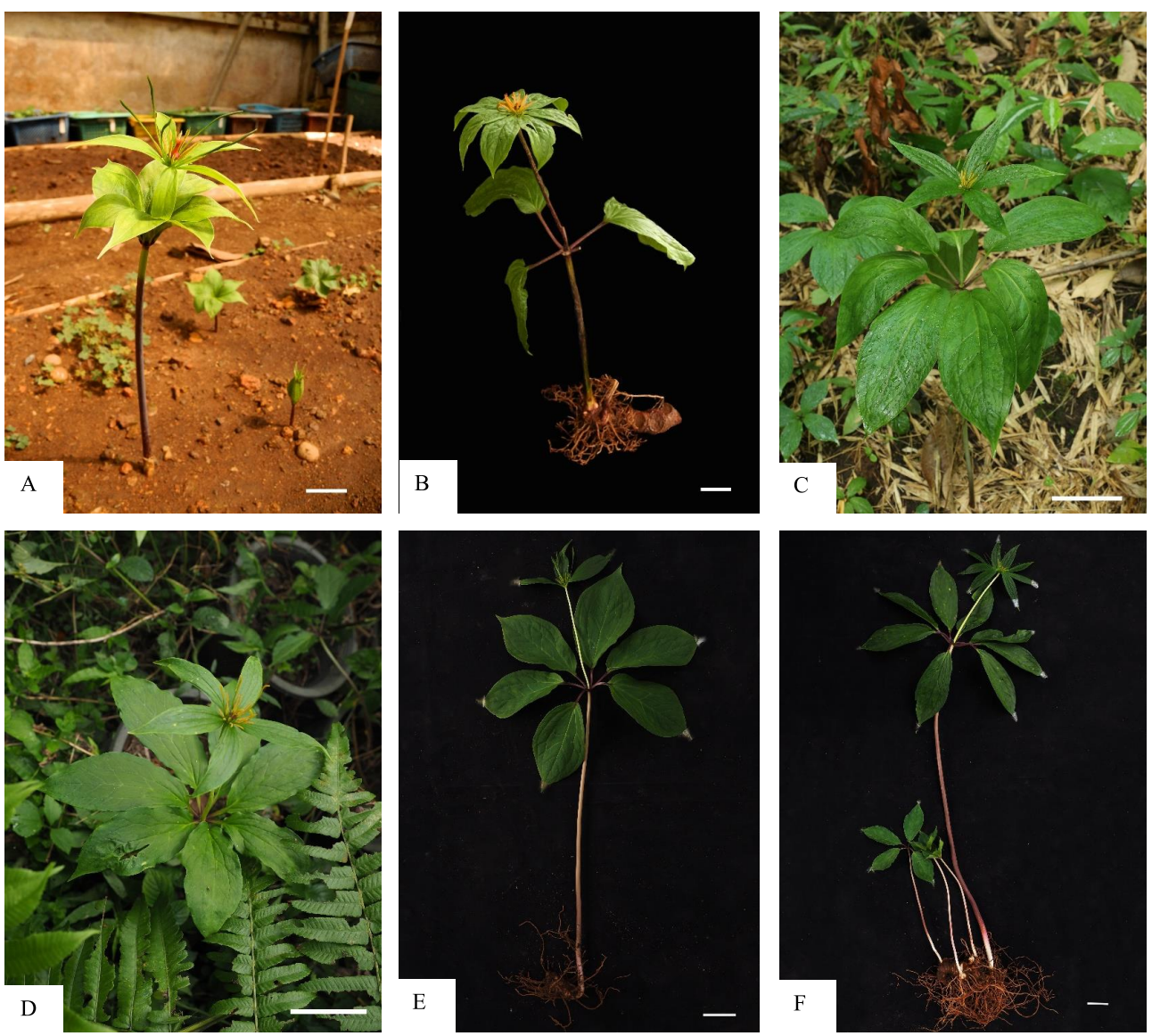

Fig. 1 Plant morphology of Paris in Thailand. (A) P. polyphylla var. chinensis (Mae Saruay, Chiang Rai); (B) P. cf. cronquistii var. cronquistii (Mae Jarim, Nan); (C) Paris sp. (Doi Pu Muen, Chiang Mai); (D) Paris sp. (Doi Saket, Chiang Mai); (E) Paris sp. (Mae Chon Luang, Chiang Mai); (F) Paris sp. (Samoeng, Chiang Mai). Scale bars represent $5 \mathrm{~cm}$.

whereas the accession from Pang Khon district is taxonomically undescribed and is therefore referred to as Paris sp. The accessions from Mae Jarim district, Nan province are identified at this stage as Paris cf. cronquistii (Takht.) H. Li var. cronquistii (Fig. 1B). The accessions from Chiang Mai province, from the districts of Doi Pu Muen (Fig. 1C), Doi Saket (Fig. 1D), Mae Chon Luang (Fig. 1E), Mae Khi, Mae Rim, Mae Taeng, Phraphutthabat Si Roi and Samoeng (Fig. 1F) are uncharacterized botanically and are thus referred to as Paris spp.

\section{Chromosome numbers and karyotypes}

The results of chromosomal investigation are summarized in Table 1. Of 20 Paris accessions examined in the present study, 12 are diploid $(2 n=2 x=10)$, 2 are triploid $(2 n=3 x=15)$, one is tetraploid $(2 n=4 x=20)$ and 5 are mixoploid accessions. No $\mathrm{B}$ chromosome was discovered.

Both accessions of $P$. polyphylla from Mae Saruay district, Chiang Rai province have the same somatic chromosome number of $2 n=2 x=10$ (Fig. 2B), therefore this species is presumably diploid with base chromosome number $x=5$. Its karyotype formula is $6 \mathrm{~m}+4 \mathrm{t}$, comprising 3 pairs of metacentric (m) chromosomes and 2 pairs of telocentric $(\mathrm{t})$ chromosomes (Fig. 3A-B). The third accession from Chiang Rai (Pang Khon district) is also diploid (Fig. 2C), but the plant morphology does not allow species identification at this stage.

The accessions of $P$. cf. cronquistii from Mae Jarim district (Nan province) turned out to be diploid (3 accessions, e.g. Fig. 2A) and triploid (1 accession, Fig. $2 \mathrm{H}$ ). The karyotype formula that could be constructed from 2 diploid accessions is $6 \mathrm{~m}+4 \mathrm{t}$ (Fig. 3C-D), which is the same as that of P. polyphylla from Chiang Rai. The triploid accession $(2 n=3 x=15$, Fig. $2 \mathrm{H})$ has the same karyotype formula as the diploids, but with 3 sets of homologous chromosomes $(9 \mathrm{~m}+6 \mathrm{t}$, Fig. 3G-H) instead of 2 . 

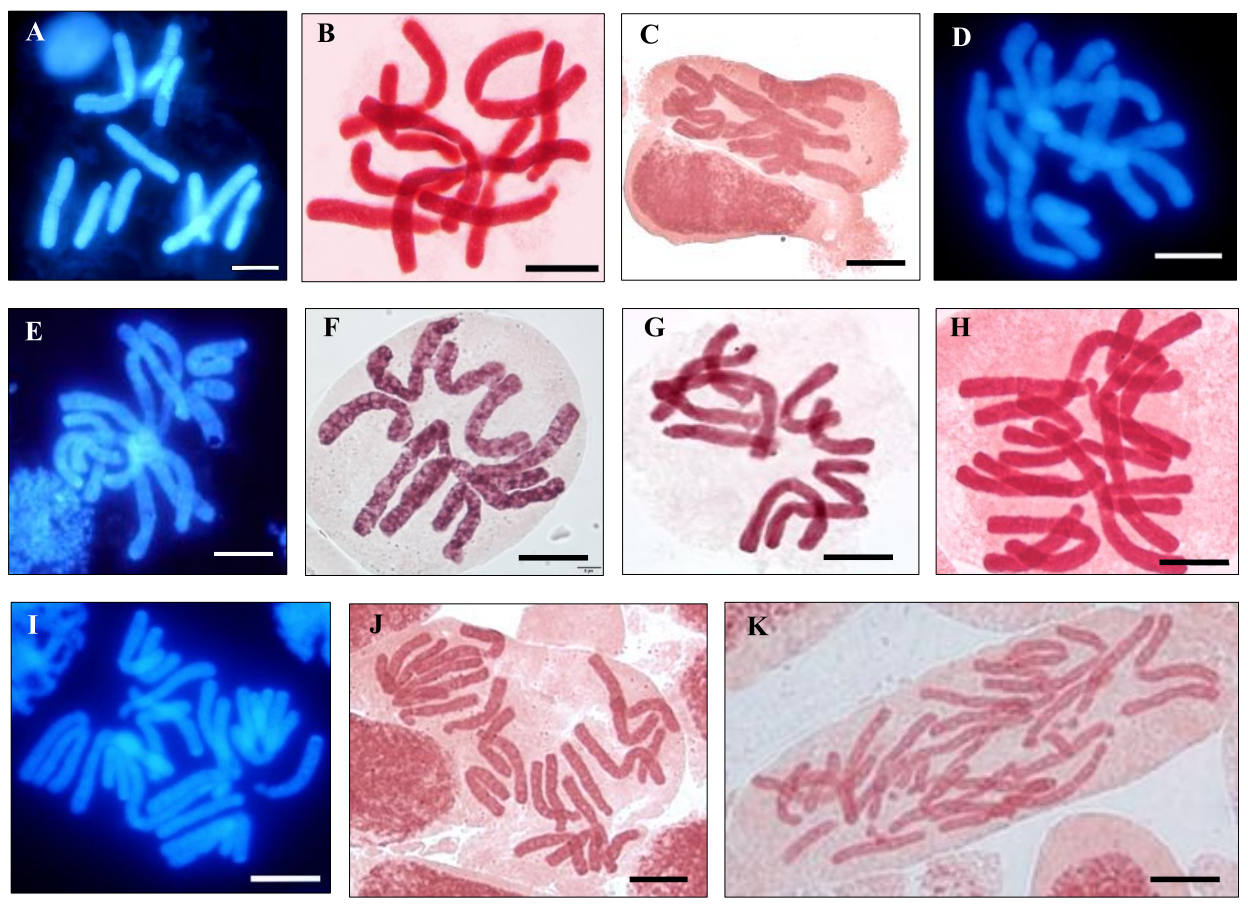

Fig. 2 Mitotic metaphase chromosomes of selected Paris accessions: (A-G) diploid cells $(2 n=2 x=10)$, (H) triploid cell $(2 n=3 x=15)$ and (I-K) tetraploid cells $(2 n=4 x=20)$. (A) Paris cf. cronquistii var. cronquistii, diploid accession PPNN 3935 (Mae Jarim, Nan); (B) P. polyphylla var. chinensis, diploid accession PP 035810 (Mae Saruay, Chiang Rai); (C) Paris sp., diploid accession PJPK 621114-1 (Pang Khon, Chiang Rai); (D) Paris sp., diploid accession PJSM2 013 (Samoeng, Chiang Mai); (E) Paris sp., 2x/3x mixoploid accession PJSM2 012 (Samoeng, Chiang Mai); (F) Paris sp., $2 x / 4 x$ mixoploid accession PJSM2 015 (Samoeng, Chiang Mai); (G) Paris sp., 2x/3x mixoploid accession PJSM2 014 (Samoeng, Chiang Mai); (H) Paris cf. cronquistii var. cronquistii, triploid accession PPNN 59059; (I) Paris sp., $2 x / 4 x$ mixoploid accession PJSM2 014 (Samoeng, Chiang Mai); (J) Paris sp., tetraploid accession PJMT 621113-3 (Mae Taeng, Chiang Mai); and (K) Paris sp., 2x/4x mixoploid accession PJPPB 62017 (Phraphutthabat Si Roi, Chiang Mai). Scale bars represent $10 \mu \mathrm{m}$.

From Chiang Mai province, the accessions are variable cytogenetically. Diploid (Fig. 2D-G), triploid and tetraploid (Fig. 2I-K) chromosome numbers were discovered. Six out of 13 accessions from Chiang Mai are diploid, and more importantly, they came from different districts. Diploids are therefore relatively widespread. The karyotype formula that could be constructed from one of these diploid accessions is $6 \mathrm{~m}+4$ st (from Doi Pu Muen), comprising 3 pairs of metacentric (m) chromosomes and 2 pairs of subtelocentric (st) chromosomes. This karyotype differs from that of $P$. polyphylla and $P$. cf. cronquistii in that it is comprised of 4 st rather than $4 \mathrm{t}$ chromosomes. An example of stchromosomes can be seen in Fig. 4C-D, i.e. the NOR bearing chromosome pair from Doi Pu Muen.

Polyploidy is apparently common among accessions from Chiang Mai province. The only Paris accession from Mae Chon Luang is triploid, but the metaphases are not sufficiently resolved for karyotype construction. In addition, one of the 2 accessions from Mae Taeng district turned out to be tetraploid (Fig. 2J). But the most unexpected feature of Paris accessions from Chiang Mai is that they are cytogenetically variable even within plants. They are mixoploid plants. Out of the 5 mixoploid accessions from Chiang Mai (Table 1), 2 have diploid and triploid cells in different roots of the same plant, i.e. PJMK 62018 from Mae Khi and PJSM2 012 from Samoeng (Fig. 2E), thus referred to here as $2 x / 3 x$ mixoploids. The other 3 are $2 x / 4 x$ mixoploid accessions, comprising diploid and tetraploid cells within the same plants and even within the same roots: accessions PJPPB 62017 from Phraphutthabat Si Roi, PJSM2 014 and PJSM2 015, both from Samoeng district. One of these 2 Samoeng accessions, i.e. PJSM2 015 (Fig. 2F), has the diploid karyotype formula $6 \mathrm{~m}+4 \mathrm{st}$, the 


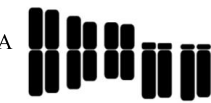
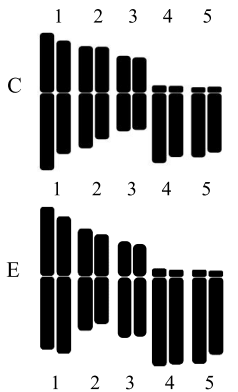

G

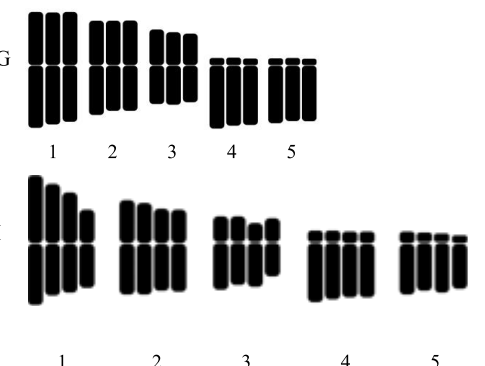

в

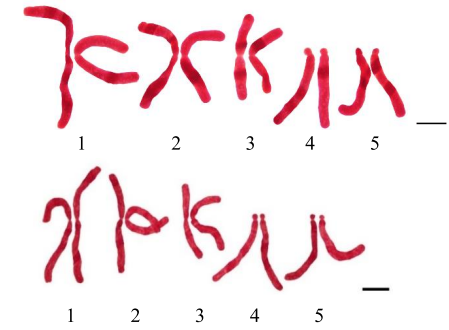

F

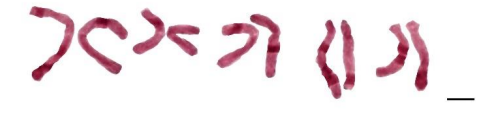

$\mathrm{H}$
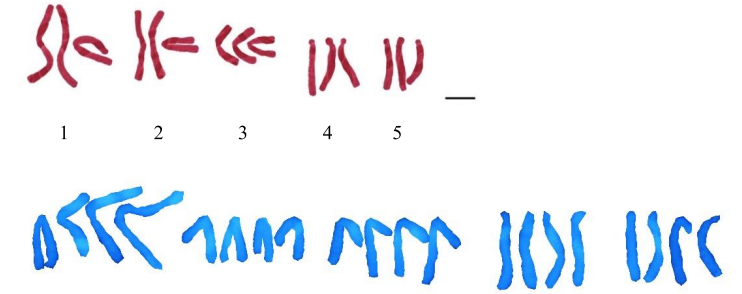

Fig. 3 Ideograms and karyotypes of Paris, showing chromosome number IDs from 1 to 5. (A-B) P. polyphylla var. chinensis, diploid accession PP 035810 (Mae Saruay, Chiang Rai), diploid cell, karyotype 6m+4t; (C-D) Paris cf. cronquistii var. cronquistii, diploid accession PPNN 59242 (Mae Jarim, Nan), diploid cell, karyotype 6m+4t; (E-F) Paris sp., $2 x / 4 x$ mixoploid accession PJSM2 014 (Samoeng, Chiang Mai), diploid cell, karyotype 4m+2sm+4st; (G-H) Paris cf. cronquistii var. cronquistii, triploid accession PPNN 59059 (Mae Jarim, Nan), triploid cell, karyotype 9m+6t; and (I-J) Paris sp., $2 x / 4 x$ mixoploid accession PJSM2 014 (Samoeng, Chiang Mai), tetraploid cell, karyotype $8 \mathrm{~m}+4 \mathrm{sm}+8$ st. Scale bars represent $10 \mu \mathrm{m}$.

same formula as that of the accession from Doi Pu Muen. The other Samoeng accession, i.e. PJSM2 014, contains both diploid (Fig. 2G) and tetraploid (Fig. 2I) cells in the same roots. The tetraploid chromosome complement of this particular accession is clearly a doubling of the diploid set as they share the same karyotype formula: $4 m+2 s m+4 s t$ for diploid (Fig. 3E-F) and $8 \mathrm{~m}+4 \mathrm{sm}+8 \mathrm{st}$ for tetraploid (Fig. 3I-J) cells. This differs from the karyotype of other Chiang Mai accessions in that it includes submetacentric $(\mathrm{sm})$ chromosomes, i.e. $4 \mathrm{~m}+2 \mathrm{sm}$ versus $6 \mathrm{~m}$ chromosomes.

\section{Ribosomal FISH mapping on chromosomes}

Two different ribosomal DNA (rDNA) probes were used in this study: 5S and 45S rDNA. The FISH experiments were conducted with chromosomes of Paris cf. cronquistii from Nan province and Paris accessions from Chiang Mai province. Examples of the FISH results are shown in Fig. 4, and the chromosomal localization of both rDNA genes is illustrated in Fig. 5.
The only diploid accession of $P$. cf. cronquistii examined by FISH showed 2 clear signals of the 45S rDNA from interphase nuclei (Fig. 4A-B), and both appeared to be associated with the nucleoli as expected. FISH signals from all other accessions under study were detected on metaphase chromosomes, and where available, the results were well supported by the interphase signals. Diploid cells of Paris accessions from Chiang Mai often showed 4 signals ( 2 pairs) of $45 \mathrm{~S}$ rDNA, most probably 1 pair major and 1 pair minor sites (Doi Pu Muen, Fig. 4CD) or 1 to 3 major sites in other accessions, i.e. Phraphutthabat Si Roi (Fig. 4E-F, both in metaphase and interphase cells) and Samoeng (Fig. 4G-H). Usually 4 sites of $45 \mathrm{~S}$ rDNA were observed among triploid and tetraploid cells in accessions from Chiang Mai province.

The most common map of 45S rDNA on chromosomes of diploid Chiang Mai accessions comprises 1 pair of loci on the terminal position of a homologous pair of metacentric (m) chromosomes and 1 pair on the short arm of subtelocen- 


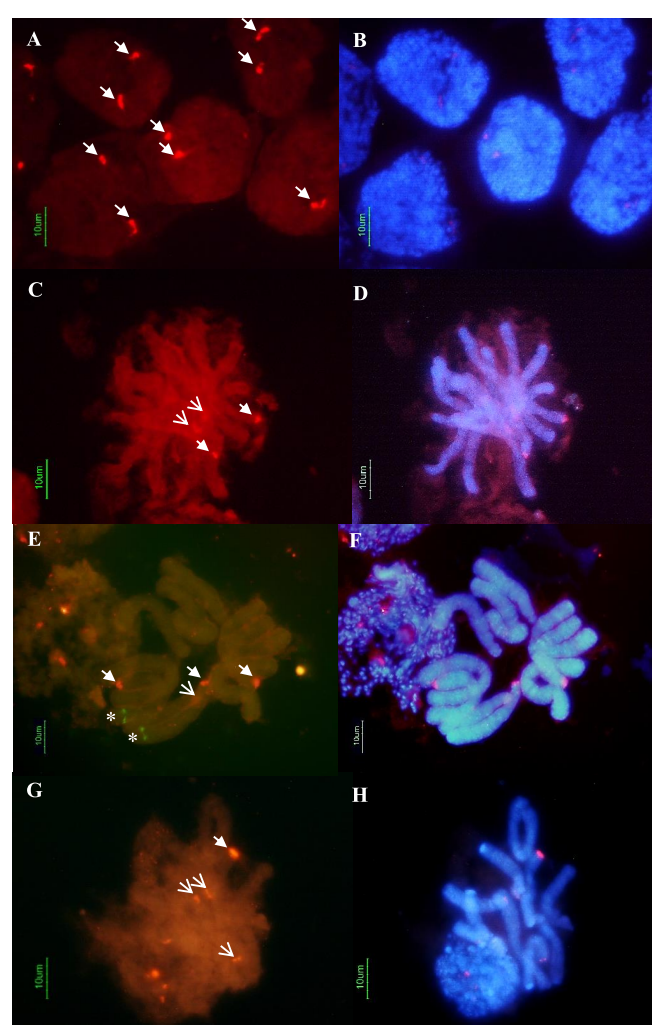

Fig. 4 Ribosomal FISH mapping on chromosomes of Paris. Arrows indicate the position of red-fluorescing 45S rDNA: closed/solid arrows indicate major sites with strong signal while open arrows mark minor sites or those with weak signal. Asterisks indicate the position of green-fluorescing $5 S$ rDNA. (A-B) Paris cf. cronquistii var. cronquistii, diploid accession PPNN 5926 (Mae Jarim, Nan), showing 2 major sites of 45S rDNA in the interphase nuclei, co-localized with the nucleoli. (C-D) Paris sp., diploid accession PJPM 62004 (Doi Pu Muen, Chiang Mai), a diploid cell showing 2 major 45S rDNA sites and 2 weak sites. (E-F) Paris sp., diploid accession PJPPB 62004 (Phraphutthabat Si Roi, Chiang Mai), showing a metaphase cell with 3 major red-fluorescing 45S rDNA sites and 1 weak (hidden) site and with 2 green-fluorescing 5S rDNA sites. The 5S and the $45 \mathrm{~S}$ sites are on the same st-chromosome but on the opposite arms. Note that the 45S rDNA sites are expressed into the nucleoli of the adjacent interphase nucleus. (G-H) Paris sp., mixoploid $2 x / 3 x$ accession PJSM2 012 (Samoeng, Chiang Mai), showing 1 major 45S rDNA site and 3 weaker sites. Scale bars represent $10 \mu \mathrm{m}$.

tric (st) chromosomes (Figs. 4 and 5). In some cases, the 45S rDNA signal on the subtelocentric pair was weak (Fig. 4E-F), but in other cases the weak signals appeared to be random, indicating that it may be due to a technical reason such as

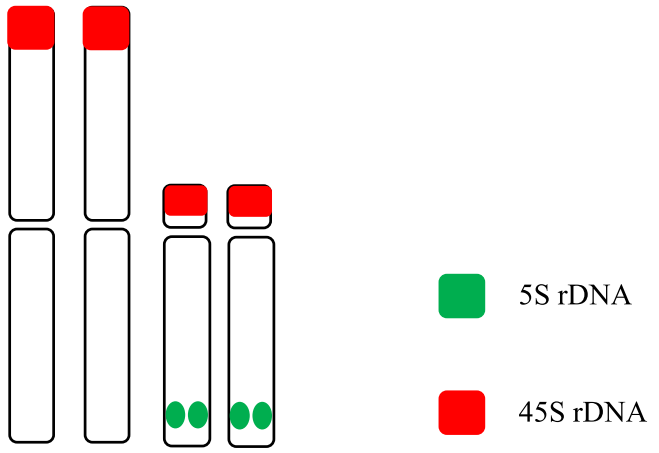

Fig. 5 Ideogram of the ribosomal FISH mapping on chromosomes of diploid Paris accessions from Chiang Mai province: PJSM2 012 (Samoeng), PJPM 62004 (Doi Pu Muen) and PJPPB 62004 (Phraphutthabat Si Roi). Red: 45S rDNA (probe pTa 71). Green: $5 \mathrm{~S}$ rDNA (probe pTa 794). Chromosomes in this ideogram do not represent actual size and shape.

chromosomal overlapping or more likely due to the reduction of the rDNA copy number in these weak sites. In addition to the major, terminal positions of the 45S rDNA sites, an interstitial location was observed in one of the mixoploid accessions from Samoeng district, the accession PJSM2 014, which also possesses the unique karyotype formula $4 \mathrm{~m}+2 \mathrm{sm}+4 \mathrm{st} /$ diploid cell (images not shown).

Generally, one pair of 5S rDNA was clearly detectable in diploid cells, although in some cases the pair comprised one strong and one weak signal. The 5S rDNA appeared on the interstitial position of the long arm of subtelocentric chromosomes, which is the same chromosome pair that bears the $45 \mathrm{~S}$ rDNA repeats on the short arm (Fig. 5, see example in Fig. 4E). The triploid accession PJMJ2 008 from Mae Chon Luang in Chiang Mai province showed 3 signals of 5S rDNA. The tetraploid cells of Samoeng accession PJSM2 014 had 4 5S rDNA sites (2 pairs), but the location on chromosomes was not clear in this study.

\section{DISCUSSION}

\section{Chromosome number and karyotypic variation among diploid Paris accessions}

Diploid Paris accessions in the present study all have the somatic chromosome number $2 n=2 x=10$. According to the Chromosome Counts Database (CCDB) [11], this $2 n$ number is the only diploid number existing in Paris genus, i.e. there is no variation in the diploid somatic number. On the other hand, we have discovered a significant variation in 
the karyotypes among the diploid accessions in the present study.

$P$. polyphylla var. chinensis and $P$. cf. cronquistii var. cronquistii share the same basic karyotype formula of $6 \mathrm{~m}+4 \mathrm{t}$, and this is in good agreement with other studies. P. polyphylla var. chinensis from diverse locations in China has the same basic karyotype as in our study, i.e. $6 \mathrm{~m}+4 \mathrm{t}[9,10,20,24]$. In addition, $P$. polyphylla var. yunnanensis is characterized by this basic karyotype $[10,14,21]$. Karyotype of $P$. cronquistii is also $6 \mathrm{~m}+4 \mathrm{t}$ [25].

Our study revealed 2 other karyotype formulae from Chiang Mai accessions: $6 \mathrm{~m}+4 \mathrm{st}$ and $4 m+2 s m+4 s t$. The presence of subtelocentric (st) chromosomes in Paris karyotypes appears to be prevalent among temperate taxa, in contrast to telocentric $(\mathrm{t})$ chromosomes that are typical of the tropical taxa $[8,25]$. Examples of karyotypes containing st-chromosomes in the literatures include: $6 \mathrm{~m}+1 \mathrm{st}+3 \mathrm{t}$ in $P$. polyphylla var. stenophylla Franch. from southern China [24] and P. marmorata Stearn from relatively high elevations in Sichuan and north of the Indian subcontinent [9]; $6 \mathrm{~m}+2 \mathrm{st}+2 \mathrm{t}$ in $P$. polyphylla var. polyphylla from relatively low elevations in Sichuan province, southwestern China [9]; and $6 \mathrm{~m}+4 \mathrm{st}$ in $P$. bashanensis F.T. Wang \& Tang from medium to high elevations also in Sichuan [24]. There seems to be 2 main karyotypes containing st-chromosomes, the 2 st and the 4 st types. The former tends to be widespread in the temperate regions such as in western China and east of the Tibetan Plateau whereas the latter appears to be confined to the border region between the temperate and subtropical zones such as further north of Thailand into South China [25]. In contrast, the basic karyotype without st-chromosomes, i.e. $6 \mathrm{~m}+4 \mathrm{t}$, is more prevalent in the subtropical and tropical regions of Asia such as that found in $P$. polyphylla var. chinensis and $P$. cf. cronquistii in our study.

In terms of karyotype symmetry, Stebbins [15] explained the general trend of karyotype evolution in plants where the karyotype symmetry is primary, and the asymmetry is evolutionarily more advanced. Thus, the karyotype evolutionary pattern among Paris taxa should be in the direction from 4 st to $2 \mathrm{st}$ and then $4 \mathrm{t}$. Indeed, the dataset compilation paper [26] shows that chromosomes evolve in a direction from symmetry to asymmetry. This is consistent with the observations that many genera show increasing asymmetry and thus, it may be a widespread karyotypic feature in Angiosperms [15]. Various types of chromosome rearrangements in- cluding breakages and reciprocal translocations of unequal chromosome segments are likely to drive the symmetry towards the asymmetry [15]. In view of this trend in chromosomal evolution, it is possible that Chiang Mai accessions possessing the 2 different basic karyotypes, i.e. $6 m+4 s t$ and $4 m+2 s m+4 s t$, belong to 2 different species. This, however, requires further investigation incorporating morphological description and phylogenetic analysis. Karyotypes of other accessions from Chiang Mai are not available at this stage.

\section{Ribosomal FISH provides important insights into the chromosomal evolution in Paris}

The ribosomal FISH mapping supports that certain Chiang Mai accessions belong to species different from $P$. polyphylla var. chinensis and $P$. cf. cronquistii var. cronquistii. The Paris accessions from Chiang Mai having different karyotypes, i.e. $6 \mathrm{~m}+4 \mathrm{st}$ and $4 m+2 s m+4 s t$, also have different ribosomal FISH maps. The former has $45 \mathrm{~S}$ rDNA map as in the ideogram in Fig. 5 (one pair m-terminal and one pair st-terminal), but the latter has a different map consisting of one site st-terminal, one site $\mathrm{m}$ interstitial and one pair sm-terminal.

To the best of our knowledge, there are only 2 references on ribosomal FISH mapping on chromosomes of Paris $[20,21]$. Neither of these 2 studies has detected 45S rDNA loci on subtelocentric (st) chromosomes, which is in direct contrast with our study. In addition, the interstitial $\mathrm{m}$ - and the terminal sm-sites discovered in the present paper are novel. In one paper [20], 45S rDNA sites were observed at the terminal position on the short arm of telocentric (t) chromosomes, on both pairs in $P$. polyphylla (karyotype $6 \mathrm{~m}+4 \mathrm{t}$ ) but only one pair in $P$. tetraphylla and $P$. verticillata (both species have karyotype $6 \mathrm{~m}+2 \mathrm{st}+2 \mathrm{t}$ ). The other paper [21] reported 2 terminal pairs of 45S rDNA: one pair on the third (m) metacentric and one pair on the first t-chromosomes of $P$. polyphylla var. yunnanensis, $P$. forrestii and $P$. axialis (all share the karyotype $6 \mathrm{~m}+4 \mathrm{t})$. The pattern is indeed similar to the rDNA map in our study (Fig. 5), differing only in that the t-chromosomes in their study are st-chromosomes in our Chiang Mai accessions.

Based on the comprehensive analysis of the distribution of 45S rDNA sites on chromosomes obtained by FISH together with other karyotypic data from 846 plant species [27], the rDNA sites in angiosperms tend to be on the short arms, mainly in the terminal regions. The results of rDNA FISH mapping on Paris chromosomes, both in the present 
study and from other papers, thus fall well within this general pattern. This distribution of sites may be related to karyotype characteristics or chromosomal organization of specific taxa. For example, during interphase, centromeres are often clustered in one pole of the cell and telomeres in the opposite pole as a consequence of the anaphase movement. This kind of chromosome distribution in the nucleus is named Rabl orientation. Terminal or subtelomeric $45 \mathrm{~S}$ rDNA sites, as opposed to proximal sites, clearly have an advantage when it comes to transcribing ribosomal genes into the nucleolus. The distal half of cereal chromosomes at interphase has been captured by electron microscopy to be highly decondensed [28], and it is exactly this decondensed region that is more accessible for transcriptional enzymes and substrates. In contrast, extra or additional sites of 45S rDNA can be found elsewhere along chromosome arm. These other locations are probably inactive, or they are non-transcribed sites. Such is the case of the interstitial 45S rDNA sites in Paris accessions from Samoeng district in Chiang Mai. The occurrence of extra sites may have been associated with polyploidization events. Paris accessions from Samoeng district are indeed very diverse (see Table 1), comprising diploid, polyploid and mixoploid accessions.

This study is the first to report the mapping of $5 \mathrm{~S}$ ribosomal repeats on chromosomes of Paris. Typical 5S rDNA map observed in the Paris accessions from Chiang Mai province comprises interstitial site on the long arm of the same st-chromosomes as the 45S rDNA (Fig. 5). This is an interesting feature of ribosomal gene distribution in the plant genome; both ribosomal multigene families reside on the same chromosome. In most species, $5 \mathrm{~S}$ and $45 \mathrm{~S}$ rDNA sites are localized on different chromosomes, but the occurrence of both sites on the same chromosome (here referred to as linked sites) has been reported in several species, sometimes in adjacent positions [29, 30]. In the analysis of 166 angiosperm karyotypes with 5S and 45S rDNA localization [29], $13.3 \%$ of them show sites on the same chromosome, and in $8.4 \%$ of karyotypes the sites are adjacent. Their analyses further reveal that 5S-45S linked sites may have arisen by chance as a consequence of random transpositions of both sequences. Interestingly, transposable elements have been found flanking 5S rDNA sequences or tightly associated with them in different species [31], supporting the putative role of these elements on the mobility and origin of new sites. The presence of 5S-45S linked sites in a genus can be used for tracing ancestry among species in the phylogenetic and phylogeographical context, for example, among taxonomically related barley (Hordeum L.) species across Asia and America [32]. The retention of adjacent sites in an extensive taxonomic lineage has been observed in a number of plant families $[29,33]$. For Paris, further experiments of simultaneous FISH mapping of $5 \mathrm{~S}$ and $45 \mathrm{~S}$ rDNA on chromosomes from more accessions would provide evidence useful for resolving evolutionary relationships among closely related species and for the purpose of taxonomic classification of this genus.

\section{Some Paris accessions are triploid, tetraploid or mixoploid}

Of 20 Paris accessions examined in this study, 2 are triploid, one is tetraploid and 5 are mixoploid accessions (Table 1). One of the accessions belonging to $P$. cf. cronquistii is triploid with $2 n=$ $3 x=15$ and karyotype $9 \mathrm{~m}+6 \mathrm{t}$. But according to CCDB [11], P. cronquistii is a diploid species. One Paris accession from Chiang Mai is also a triploid; it is the only accession coming from Mae Chon Luang district. The CCDB database that keeps more than a hundred of chromosome number records from Paris species worldwide, however, contains a very rare occurrence of the triploid number, i.e. only in the temperate Eurasian species, $P$. quadrifolia, which is normally a tetraploid. This triploid number seems to have come from a Russian survey of Siberian plants (reference not accessible). Our data on triploidy, on the other hand, are more explicit. The triploid $P$. cf. cronquistii accession has the exact karyotype formula as the diploid ones, i.e. with 3 sets of chromosomes rather than 2 . It is therefore likely that this accession is an autotriploid, arising spontaneously within the diploid population.

The ribosomal FISH results indicate that the triploid accession from Mae Chon Luang district in Chiang Mai is also an autotriploid as we detected 3 homologous 5S DNA sites. A triploid individual can also arise from hybridization between diploid and tetraploid parents. Such hybrids are thought to promote tetraploid establishment by being a triploid bridge mediating gene flow between the species via back-crossing fertilization in the same way as documented in other plant species [34]. Indeed, we found a tetraploid accession from Mae Taeng district of Chiang Mai province.

Several cytological mechanisms are known to induce polyploidy in plants. As for this autotriploidy in Paris, it is most likely that it involves the union of reduced $(1 n)$ and unreduced $(2 n)$ gametes, which 
are produced during micro- or mega-sporogenesis of the diploid plants. Unreduced $2 n$ gametes have been identified in many plant taxa, and there is strong circumstantial evidence that unreduced gametes are often involved in the formation of spontaneous polyploids [35]. In the context of cultivation or utilization of Paris, triploid plants may be more desirable compared to diploid plants, for example, for having larger rhizomes. The large rhizome size of triploid cultivars of phytoestrogen-producing plants in the genus Curcuma L. (Zingiberaceae, the ginger family) makes these plants more popular among growers in Thailand as it is believed that they may produce a higher medicinal yield [36]. Triploid and other high-ploid plants tend to have larger size than their diploid relatives [37]. This is consistent with the morphological observation of Paris plants in the present study. Samples found in Nan and Chiang Mai provinces (mixed-ploidy populations) are generally larger than those from Chiang Rai province (the diploid population).

Much to our surprise, we found mixoploids from Chiang Mai province. Two accessions (1 from Mae Khi and 1 from Samoeng) are $2 x / 3 x$ mixoploid containing diploid and triploid roots of the same plant, and 3 accessions (1 from Phraphutthabat Si Roi and 2 from Samoeng) are $2 x / 4 x$ mixoploid with both diploid and tetraploid cells in the same plant. To the best of our knowledge, the present study is the first to report mixoploidy in the genus Paris.

The situation of mixoploidy with diploid and tetraploid cells co-existing in the same plant indicates that tetraploidy in this case is formed via an endoreduplication. It is the process by which endocycling of the mitotic cell division occurs in plant cells and tissues [35]. The process could eventually lead to the formation of a new tetraploid plant, otherwise the plants stay on as chimeric- or mixoploids. Endoreduplication is common in plants with approximately $90 \%$ of herbaceous angiosperms being endopolyploid [38]. Endoreduplication is believed to have the role in compensating the plants when experiencing environmental stresses by increasing chromosome number this way and therefore gene copy number. This provides a means of increasing expression of vital genes such as genes responsible for more growth and better tolerance to stresses [39]. Further cytogenetic investigation of Paris taxa with larger sample size and better geographical or habitat resolution may reveal some ecological association with the ongoing mixoploidy in this mountainous area of northern Thailand.
Acknowledgements: This research was supported by Plant Genetics Conservation Project under the Royal initiative of Her Royal Highness Princess Maha Chakri Sirindhorn (RSPG), National Research Council of Thailand (NRCT), Biodiversity-Based Economy Development (BEDO), the Center of Excellence on Biodiversity (CEB), Erasmus Mundus Scholarship 2018, Mahidol University and University of Iceland. We are grateful to Assist. Prof. Thaya Jenjittikul, Mahidol University and Dr. Piyakaset Suksathan, Queen Sirikit Botanic Garden (QSBG) for their supervision on the taxonomic identification. We thank all the staffs from the Cytogenetic Research Laboratory at the Department of Plant Science, Faculty of Science, Mahidol University for their technical support.

\section{REFERENCES}

1. Sharma A, Kalita P, Tag H (2015) Distribution and phytomedicinal aspects of Paris polyphylla Smith from the Eastern Himalayan Region: A review. Tang 5, 1-12.

2. Liang S-J, Soukup VG (2020) PARIS Linnaeus, Sp. Pl. FOC 24, 88-95.

3. Duan B-Z, Wang Y-P, Fang H-L, Xiong C, Li X-W, Wang P, Chen S-L (2018) Authenticity analysis of Rhizoma Paridis using barcoding coupled with high resolution melting (Bar-HRM) analysis to control its quality for medicinal plant product. Chin Med 13, ID 8.

4. Dai S-X, Li W-Z, Han F-F, Guo Y-C, Zheng J-J, Liu JQ, Wang Q, Gao Y-D, et al (2016) In silico identification of anti-cancer compounds and plants from traditional Chinese medicine database. Sci Rep 6, ID 25462.

5. Man SL, Wang YL, Li YY, Gao WY, Huang XX, Ma CY (2013) Phytochemistry, pharmacology, toxicology and structure-cytotoxicity relationship of Paridis rhizome saponin. Chin Herb Med 5, 33-46.

6. Yang C, Cai H, Meng X (2016) Polyphyllin D induces apoptosis and differentiation in K562 human leukemia cells. Int Immunopharmacol 36, 17-22.

7. Ruamrungsri N, Siengdee P, Sringarm K, Chomdej S, Ongchai S, Nganvongpanit K (2016) In vitro cytotoxic screening of 31 crude extracts of Thai herbs on a chondrosarcoma cell line and primary chondrocytes and apoptosis effects of selected extracts. textitIn Vitro Cell Dev Biol-Animal 52, 434-444.

8. Hong DY, Zhu XY (1987) Cytotaxonomical studies on Liliaceae (S. L.) (1) Report on karyotypes of 10 species of 6 genera. Acta Phytotaxon Sin 25, 245-253.

9. Yue H, Ding C, Yang R, Zhang L, Zhou Y, Yan L (2011) Karyomorphology of some taxa of Paris (Melanthiaceae) from Sichuan province, China. Caryologia 64, 288-296.

10. Cheng H, Zhou Q, Li X, Zhou Y, Yang R, Zhang L, 
Ding C (2014) C-banding patterns in six taxa of Paris (Melanthiaceae). Caryologia 67, 106-109.

11. Rice A, Glick L, Abadi S, Einhorn M, Kopelman NM, Salman-Minkov A, Mayzel J, Chayet O, et al (2015) The Chromosome Counts Database (CCDB) - a community resource of plant chromosome numbers. New Phytol 206, 19-26.

12. Darlington CD (1941) Polyploidy, crossing-over, and heterochromatin in Paris. Ann Bot 5, 203-216.

13. Löve Á, Löve D (1975) Cytotaxonomical Atlas of the Arctic Flora, Lubrecht \& Cramer, Vaduz.

14. Miyamoto J, Kurita S, Gu Z, Li H (1992) C-banding patterns in eighteen taxa of the genus Paris sensu Li, Liliaceae. Cytologia 57, 181-194.

15. Stebbins GL (1971) Chromosomal Evolution in Higher Plants, J.W. Arrowsmith Ltd, Bristol.

16. Smith MC, Ingram R (1986) Heterochromatin banding in the genus Paris. Genetica 71, 141-145.

17. De Jong JH, Fransz P, Zabel P (1999) High resolution FISH in plants - techniques and applications. Trends Plant Sci 4, 258-263.

18. Soontornchainaksaeng P, Anamthawat-Jónsson K (2011) Ribosomal FISH mapping reveals hybridity in phytoestrogen producing Curcuma species from Thailand. Plant Syst Evol 292, 41-49.

19. Lucía V, Rico E, Anamthawat-Jónsson K, MartínezOrtega MM (2019) Cytogenetic evidence of a new genus of the Triticeae (Poaceae) endemic to the Iberian Peninsula: description and comparison with related genera. Bot $J$ Linn Soc 191, 523-546.

20. Miyamoto J, Ohnido N, Fukui K (1999) Physical mapping of $18 \mathrm{~S}$ rDNA by fluorescence in situ hybridization (FISH) in the three species of the genus Paris L., Liliaceae. Cytologia 64, 175-180.

21. Wang L, Li YF, Tang RH, Gu ZJ (2004) Mapping of 18-26S rDNA loci in four species of the genus Paris by fluorescence in situ hybridization (FISH). Acta Phytotaxon Sin 42, 419-426.

22. Soontornchainaksaeng $\mathrm{P}$, Jenjittikul $\mathrm{T}$ (2010) Chromosome number variation of phytoestrogenproducing Curcuma (Zingiberaceae) from Thailand. J Nat Med 64, 370-377.

23. Levan A, Fredga K, Sandberg AA (1964) Nomenclature for centromeric position of chromosomes. Hereditas 52, 201-220.

24. Gu Z, Na H (1986) Karyotype studies in eight taxa of Paris. Acta Bot Yunn 8, 313-318.

25. Gu Z, Li H (1988) Cytotaxonomic study on the genus
Paris. Acta Bot Yunn 10, 125-137.

26. Liang G, Chen H (2015) Scaling chromosomes for an evolutionary karyotype: A chromosomal trade-off between size and number across woody species. PLoS One 10, e0144669.

27. Roa F, Guerra M (2012) Distribution of 45S rDNA sites in chromosomes of plants: Structural and evolutionary implications. BMC Evol Biol 12, ID mbox225.

28. Anamthawat-Jónsson K, Heslop-Harrison JS (1990) Centromeres, telomeres and chromatin in the interphase nucleus of cereals. Caryologia 43, 205-213.

29. Roa F, Guerra M (2015) Non-random distribution of $5 S$ rDNA sites and its association with 45S rDNA in plant chromosomes. Cytogenet Genome Res 146, 243-249.

30. García S, Kovarik A, Leitch, AR, Garnatje T (2017) Cytogenetic features of rRNA genes across land plants: analysis of the plant rDNA database. Plant J 89, 1020-1030.

31. Kalendar R, Tanskanen J, Chang W, Antonius K, Sela H, Peleg O, Schulman AH (2008) Cassandra retrotransposons carry independently transcribed $5 \mathrm{~S}$ RNA. P Natl Acad Sci USA 105, 5833-5838.

32. Taketa S, Ando H, Takeda K, von Bothmer R (2001) Physical locations of 5S and 18S-25S rDNA in Asian and American diploid Hordeum species with the I genome. Heredity 86, 522-530.

33. Barros e Silva AE, Soares Filho WS, Guerra M (2013) Linked 5S and 45S rDNA sites are highly conserved through the subfamily Aurantioideae (Rutaceae). $\mathrm{Cy}$ togenet Genome Res 140, 62-69.

34. Anamthawat-Jónsson K (2019) Hybrid introgression: the outcomes of gene flow. ScienceAsia 45, 203-211.

35. Ramsey J, Schemske DW (1998) Pathways, mechanisms, and rates of polyploidy formation in flowering plants. Annu Rev Ecol Evol Syst 29, 467-501.

36. Puangpairote T, Maknoi C, Jenjittikul T, Anamthawat-Jónsson K, Soontornchainaksaeng P (2016) Natural triploidy in phyto-oestrogen producing Curcuma species and cultivars from Thailand. Euphytica 208, 47-61.

37. Otto SP (2007) The evolutionary consequences of polyploidy. Cell 131, 452-462.

38. Nagl W (1976) DNA endoreduplication and polyteny understood as evolutionary strategies. Nature 261, 614-615.

39. Paige KN (2018) Overcompensation, environmental stress, and the role of endoreduplication. Amer $J$ Bot 105, 1105-1108. 